\section{Endoscopic Nd:YAG Laser Therapy for Esophageal Wallstent Occlusion Due to Tumor Ingrowth}

Endoprosthetic procedures such as Wallstent insertion with endoscopic laser therapy can be used to palliate dysphagia in malignant esophageal obstruction (1). Recanalization of the stent lumen can be achieved by endoscopic irrigation, laser therapy, diathermy, or stent replacement (2). However, there is no accepted treatment modality to restore the luminal patency if a self-expanding metallic stent is occluded due to tumor ingrowth (3).

A woman aged 35 was admitted with a six-month history of dysphagia. Esophagoscopy revealed an infiltrating mass at $35 \mathrm{~cm}$ from the incisiors, and the evaluation showed adenocarcinoma. Peritoneal fluid analysis revealed malignant cells. A self-expanding metal stent (Wallstent, Schneider, Minnesota) was therefore inserted into the esophagus in this inoperable patient to relieve obstruction. Since dysphagia recurred and the barium swallow showed partial occlusion of the stent after three months, another Wallstent was placed inside the first one. The second stent also became occluded due to tumor ingrowth during the following three months. Since further stent placement was inappropriate, a MediLas Nd:YAG laser with an antegrade approach was used to restore the lumen in two sessions with 12,000 J (Figure 1,2). There was no documented complication. The patient did not develop stent occlusion, and died of liver metastasis five months after the laser therapy.

In this patient Wallstents were placed for the palliation of tumorinduced dysphagia. Because these stents have openings between the wire filaments, tumor ingrowth is a significant complication $(3,4)$. Insertion of a second or third stent is a possible method of treatment $(3,4)$, but each new stent causes further narrowing of the esophageal lumen. Experience regarding laser therapy for the treatment of first-stent occlusions was limited $(2,4,5)$. Since laser application has the advantage of opening up the lumen completely, we suggest alleviating dysphagia due to tumor ingrowth by using Nd:YAG laser treatment, especially with occluded second stents. Nd:YAG laser treatment is an effective way of relieving obstruction. especially in an occluded second Wallstent, due to tumor ingrowth or overgrowth.

\section{H. Simsek, G. Öksuzoğlu, O. Akhan}

Depts. of Gastroenterology and Radiology, Hacettepe University Medical School, Ankara, Turkey

\section{References}

1. Lindberg CG, Cwikiel W, Ivancev K, Lundstedt C, Stridbeck H, Tranberg KG. Laser therapy and insertion of Wallstents for palliative treatment of esophageal carcinoma. Acta Radiol 1991: $32: 345-8$.

2. Neuhaus H, Hoffmann W, Dittler HJ, Niedermeyer HP, Classen M. Implantation of self-expanding esophageal metal stents for palliation of malignant dysphagia. Endoscopy 1992; 24: 40510.

3. Wu WC, Katon RM, Saxon RR, Barton RE, Uchida BT, Keller FS, et al. Silicone-covered self-expanding metallic stents for the palliation of malignant obstruction and esophagorespiratory fistulas: experience in 32 patients and review of the literature. Gastrointest Endosc 1994: 40: 22-32.

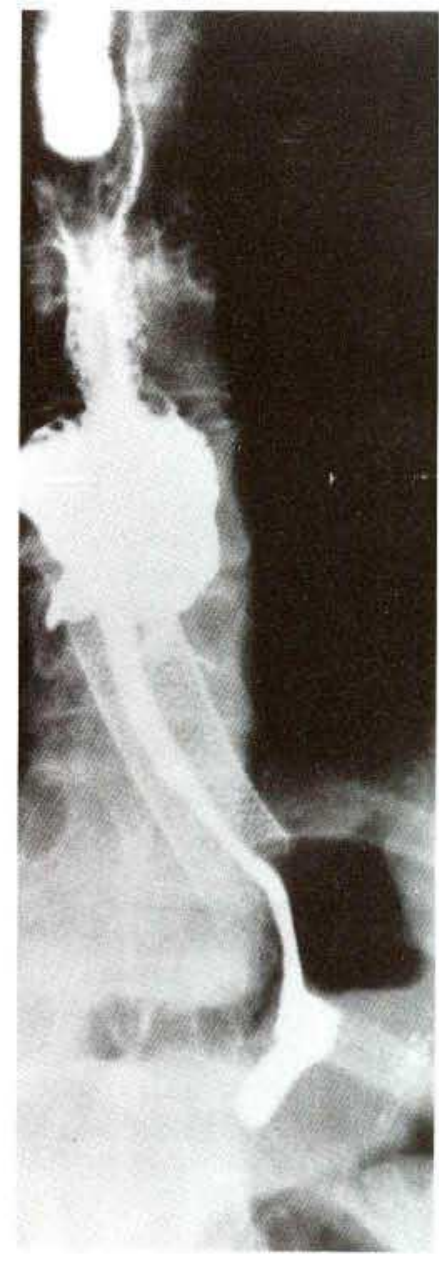

Figure 1: Barium swallow radiograph of the esophagus before laser therapy.

4. Knyrim K, Wagner HJ, Bethge N, Michael K, Vakil N. A controlled trial of an expansile metal stent for palliation of esophageal obstruction due to inoperable cancer. N Eng J Med 1993; 329: $1302-7$.

5. Bethge N, Knyrim K, Wagner HJ, Starck E, Pausch J, Kleist DV. Self-expanding metal stents for palliation of malignant esophageal obstruction: a pilot study of eight patients. Endoscopy $1992 ; 24: 411-5$.

\section{Corresponding Author}

H. Simsek, M.D.

Dept. of Gastroenterology

Hacettepe University Medical School

0600 Yuka Ayrancı

Ankara

Turkey 